\title{
Erratum to: First hyperpolarizability of cyclooctatetraene modulated by alkali and alkaline earth metals
}

Ria Sinha Roy ${ }^{1} \cdot$ Avijit Mondal $^{1} \cdot$ Prasanta K. Nandi ${ }^{1}$

Published online: 4 October 2017

(C) Springer-Verlag GmbH Germany 2017

Erratum to: J Mol Model (2017) 23: 93

https://doi.org/10.1007/s00894-017-3273-4

The original version of this article unfortunately contained a mistake. Schemes I and II were missing. These important components are given below.

The online version of the original article can be found at https://doi.org/ 10.1007/s00894-017-3273-4

Prasanta K. Nandi

nandi_pk@yahoo.co.in

1 Department of Chemistry, Indian Institute of Engineering Science and Technology, Shibpur, Howrah 711 103, India 


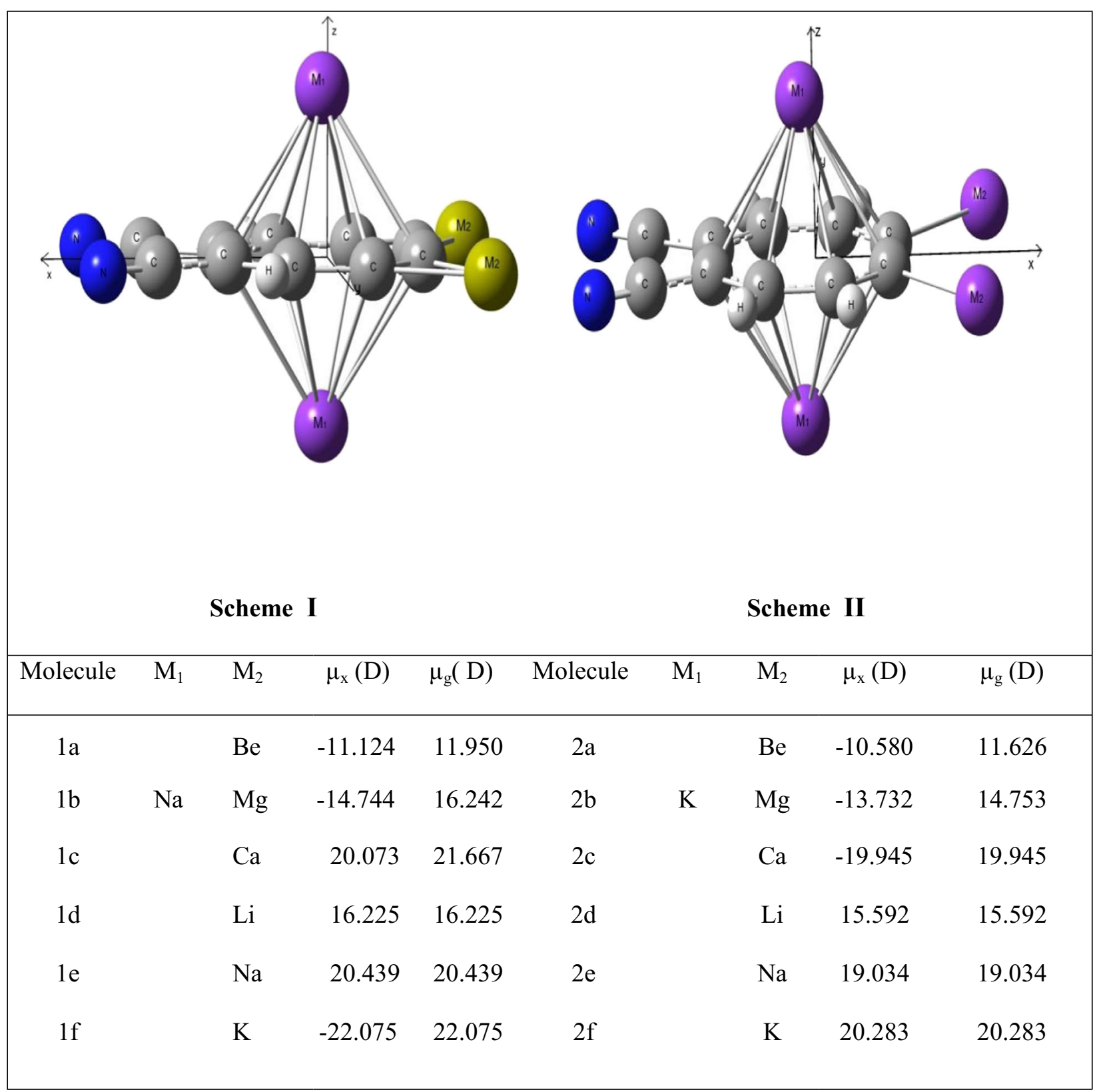

